Military Technical College

Kobry Elkobbah,

Cairo, Egypt

May 25-27,2010

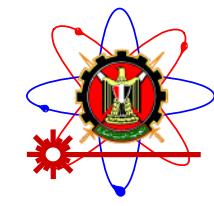

$5^{\text {th }}$ International Conference on Mathematics and Engineering Physics (ICMEP-5)

\title{
EM-19
}

\section{Static \& Dynamic Bifurcation Analysis of a coupled Acetylcholinesterase / Choline Acetyltransferase Enzymes Neurocycle}

\author{
Ibrahim G.*, and Saleh O .
}

\begin{abstract}
:
Bifurcation and Chaotic behavior of an acetylcholinesterase phemonenological two compartment model has been studied. Using Garhyan P. and Elnashaie S.S. model [1],This model describes the cholinergic neurocycle in simple form of two enzyme / two compartments. In this investigation a more realastic kinetic expression for choline acetyltransferase has been used. The bifurcation, instability and Chaotic behavior are investigated with special emphasis on neural transmission in the human brain. This type of work may be help to stimulate new research directions on brain diseases such as $\mathrm{Al}$ zheimer's and Parkinson diseases.

Keywords: Neurocycle modelling, Acetylcholinesterase/choline acetyltransferase, Bifurcation, Enzyme, Nonlinear dynamics, Dynamic simulation.
\end{abstract}

$\begin{array}{ll}E_{N} & \text { Enzyme } N \\ S_{N} & \text { Substrate } N \text { (catalyzed by enzyme } N \text { ) } \\ P_{N} & \text { Reaction product } N \text { (produced by } \mathrm{S}_{\mathrm{N}} \text { catalysed by } \mathrm{E}_{\mathrm{N}} \text { ) }\end{array}$

$\left[H^{+}\right] \quad$ Hydrogen ions concentration $\left(\mathrm{kmol} / \mathrm{m}^{3}\right.$

$\left[\mathrm{OH}^{-}\right] \quad$ Hydroxyl ions concentration $\left(\mathrm{kmol} / \mathrm{m}^{3}\right)$

$\left[S_{1}\right] \quad$ Acetylcholine concentration $\left(\mathrm{kmol} / \mathrm{m}^{3}\right)$

$\left[S_{2}\right] \quad$ Choline concentration $\left(\mathrm{kmol} / \mathrm{m}^{3}\right)$

$\left[\mathrm{S}_{3}\right] \quad$ Acetate concentration $\left(\mathrm{kmol} / \mathrm{m}^{3}\right)$

$\overline{A C h E} \quad$ Concentration of acetylcholinesterase enzyme in compartment $2(\mathrm{~kg}$ enzyme $/ \mathrm{m}^{3}$ )

$\overline{C h A T} \quad$ Concentration of choline acetyltransferase in compartment $1(\mathrm{~kg}$ enzyme $/ \mathrm{m}^{3}$ )

$K_{s 1}, K_{i 1}, K_{h 1}, K_{h h 1}$ Kinetic constants for the choline acetyltransferase catalyzed reaction $\left(\mathrm{kmol} / \mathrm{m}^{3}\right)$ 
$K_{s 2}, K_{i 2}, K_{h 2}, K_{h h^{\prime}}$ Kinetic constants for the coenzyme A catalyzed reaction $\left(\mathrm{kmol} / \mathrm{m}^{3}\right)$

$K_{s 3}, K_{i 3}, K_{h 3}, K_{h h 3}$ Kinetic constants for the acetylcholinesterase catalyzed reaction $\left(\mathrm{kmol} / \mathrm{m}^{3}\right)$

$A_{M} \quad$ area of membrane separating compartments 1 and $2\left(\mathrm{~m}^{2}\right.$

$q \quad$ Volumetric flow rate into compartment $1\left(\mathrm{~m}^{3} / \mathrm{s}\right)$

$R_{W(j)} \quad$ Rate of water formation in compartment $j\left(\mathrm{kmol} / \mathrm{m}^{3} \mathrm{~s}\right)$

$R_{(j)} \quad$ Rate of reaction in compartment $j\left(\mathrm{kmol} / \mathrm{m}^{3} \mathrm{~s}\right)$

$R \quad$ Recycle flow rate ratio

$V_{(j)} \quad$ Volume of compartment $j\left(\mathrm{~m}^{3}\right)$

$t \quad$ Time (s)

$K_{W} \quad$ Equilibrium constant for water $\left(\mathrm{kmol}^{2} / \mathrm{m}^{6}\right)$

$\alpha_{H^{+}}^{\prime} \quad$ Membrane permeability for hydrogen ions $(\mathrm{m} / \mathrm{s})$

$\alpha_{\mathrm{OH}^{-}}^{\prime} \quad$ Membrane permeability for hydroxyl ions $(\mathrm{m} / \mathrm{s})$

$\alpha_{S_{1}}^{\prime} \quad$ Membrane permeability for acetylcholine $(\mathrm{m} / \mathrm{s})$

$\alpha_{S_{2}}^{\prime} \quad$ Membrane permeability for choline $(\mathrm{m} / \mathrm{s})$

$\alpha_{S_{3}}^{\prime} \quad$ Membrane permeability for acetate $(\mathrm{m} / \mathrm{s})$

$\overline{C o A} \quad$ Concentration of coenzyme A in compartment $1\left(\mathrm{~kg}\right.$ enzyme $\left./ \mathrm{m}^{3}\right)$

$\mathrm{V}_{\mathrm{R}} \quad \mathrm{V} 1 / \mathrm{V} 2$

ABBREVIATIONS

\begin{tabular}{|l|l|}
\hline$A C h E$ & Acetylcholinesterase \\
\hline$C h A T$ & Choline Acetyltransferase \\
\hline$C o A$ & Coenzyme A \\
\hline$A C h$ & Acetylcholine \\
\hline$C S T R$ & continuous stirred tank reactor \\
\hline$H B$ & Hopf bifurcation \\
\hline$S B$ & Static bifurcation \\
\hline$P L P$ & Periodic limit point \\
\hline$P D$ & period doubling \\
\hline$P i$ & periodicity $i$ of the periodic orbit \\
\hline
\end{tabular}

SUBSCRIPTS

\begin{tabular}{|l|l|}
\hline 1 & Compartment 1 \\
\hline 2 & Compartment 2 \\
\hline$f$ & Feed condition \\
\hline
\end{tabular}

\section{LEGEND FOR FIGURES}

\begin{tabular}{|l|l|}
\hline- & stable steady state branch \\
\hline------ & unstable steady state branch \\
\hline
\end{tabular}




\begin{tabular}{|c|c|}
\hline$\bullet \bullet \bullet \bullet \bullet \bullet \bullet$ & stable periodic branch \\
\hline 0000000 & unstable periodic branch \\
\hline
\end{tabular}

\begin{tabular}{|l|l|}
\hline \multicolumn{2}{|l|}{ Dimensionless State Variables } \\
$h_{(j)}=\frac{\left[H^{+}\right]_{(j)}}{K_{h 1}}$ & $\begin{array}{l}\text { Dimensionless hydrogen ion concentration } \\
\text { in compartment } j\end{array}$ \\
\hline$s_{1(j)}=\frac{\left[S_{1}\right]_{(j)}}{K_{s 1}}$ & $\begin{array}{l}\text { Dimensionless acetylcholine concentration } \\
\text { in compartment } j\end{array}$ \\
\hline$s_{2(j)}=\frac{\left[S_{2}\right]_{(j)}}{\left[S_{2}\right]_{\text {reference }}}$ & $\begin{array}{l}\text { Dimensionless choline concentration in } \\
\text { compartment } j\end{array}$ \\
\hline$s_{3(j)}=\frac{\left[S_{3}\right]_{(j)}}{\left[S_{3}\right]_{\text {reference }}}$ & $\begin{array}{l}\text { Dimensionless acetate concentration in } \\
\text { compartment } j\end{array}$ \\
\hline
\end{tabular}

\section{1-Introduction:}

The causes of Alzheimer's and Parkinson's diseases ( AD/PD) are still unknown and extensive research is being carried out in order to find out the nature and causes of these diseases[8]. Theoretical, modern neuroscience recruits collaboration from a wide range of disciplines including biology, genetics, biochemistry, biophysics, pharmacology, electronics, information technology, mathematics, statistics, physics , cognitive sciences, psychology as well as chemical / biological reaction engineering. The synapse is the point of impulse transmission between neurons; impulses are transmitted from presynaptic neurons to postsynaptic neurons ( as indicated in Figure (1)). Acetylcholine plays an important role in nerve excitration[4].It is found in the cholinergic synapses that provide a stimulatory transmission in the nerveous system. (Figure (2))

\section{Figure ( 1 )}

Figure ( 2 )
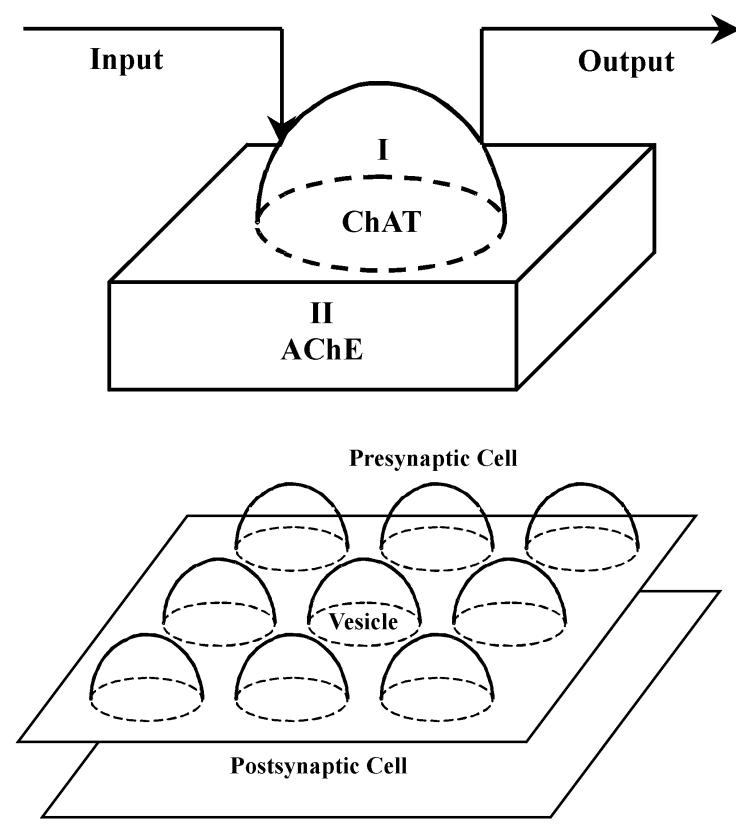


\section{Figure ( 3 )}

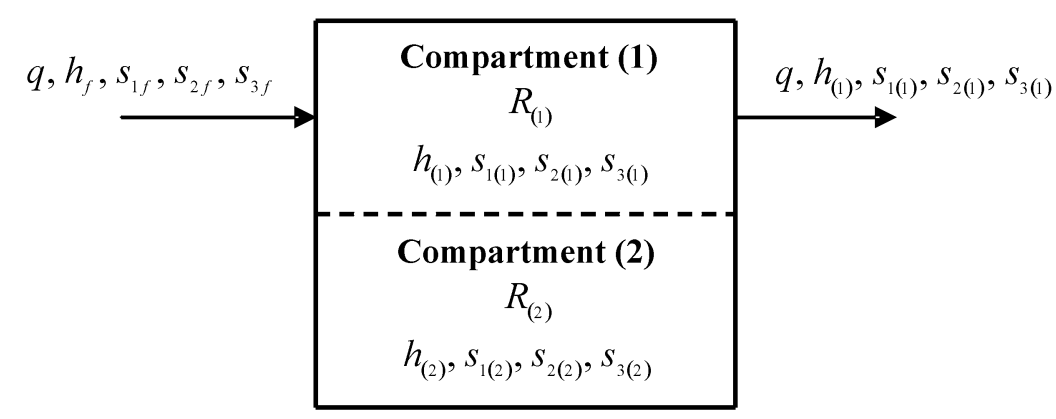

Its complete neurocycle implies a coupled two-enzymes/two- compartments model with strongly coupled events as follows :

During the activation event, acetylcholine is synthesized from choline and acetyl coenzymes A ( acetyl- CoA) by the enzyme choline acetyltransferase (ChAT) [2,3] and is immediatley stored in small vesicular compartments closely attached to the cytoplasmic side of the presynaptic membranes[6].During the degradation event, the synaptic cleft degradation begins for removing the remaining acetylcholine [7].This occurs through destruction ( hydrolosis) of acetylcholine by the acetylcholinesterase enzyme ( AchE ) to form choline and acetic acid[1,5,7].

Diffusion-reaction models may be an important in understanding neural transmission

And in the struggle against cholinergic brain diseases such as Alzheimer's and Parkinson's which are a result of an imbalances of the cholinergic system considered above [8,9].Parag \& Elnashaie have investigated the bifurcation, instability and chaotic behavior of a two compartment model describing the complete neurocycle of acetylcholinesterase / Choline acetyltransferase ( AchE / ChAT). There study has been based on general kinetic expression of acetyltransferase activity . In this paper a more realistic kinetic expression has been used, in order to obtain more insight into such neurocycle.

\section{2- The Simplified Diffusion-Reaction Two-Enzymes/ Two - Compartments Model:}

Describing in simple form the AchE / ChAT enzymes system inside the neural synaptic cleft (Figure 1). The complete neurocycle of the acetylcholine as a neurotransmitter is simulated as a simplified two-enzymes /two-compartments model. Each compartment is described as a constant flow, constant volume, isothermal, continuous stirred tank reactor ( CSTR ). The two compartments are separated by a nonselective, permeable membrane as shown in Figures 2 and 3.

Assuming that all the events are homogeneous in all vesicles, and using the proper dimensionless state varaiables and parameters, We consider the behavior for a single synaptic vesicles as described by this simple two compartment model, where [I] and [II] denote compartments ( 1 ) and ( 2 ).

It is assumed that acetylcholine is synthesized in the presynaptic cell by the enzyme choline acetyltransferase due to an activation reaction ( where the stimulatory neurotransmitter acetylcholine is synthesized) $R_{(1)}$ as follows:

$$
\mathrm{R}_{(1):} \quad \text { Choline + Acetyl-CoA_ChAT Asetylcholine + CoA }
$$


Acetylcholine is destroyed ( hydroysed) in the postsynaptic cell by the enzyme acetylcholinesterase through a degradation reaction ( where the stimulatory neurotransmitter acetylcholine is degraded ) $R_{(2)}$ as follows:

$$
\mathrm{R}_{(2)}: \quad \text { Acetylcholine }+ \text { AchE } \quad \text { Choline }+ \text { Acetate }+\mathrm{H}^{+}
$$

- Both reactions are considered to be substrate inhibited and hydrogen ions rate dependent. This leads to a non-monotonic of the reaction rates on both the substrate and $\mathrm{PH}$.

- From an enzyme kinetics point of view, we have used the kinetic expression evaluated by Louis B. Hersh et al ( 1977)[2] which describes the choline- acetyltransferase reaction instead of the general expression used by Elnashaie, Parage. This kinetics relates the velocity of reaction by the two reactants (Choline and acetate ). The saturation constant $\mathrm{Ks}$ for this reaction is assumed to be depending on $\mathrm{H}^{+}$ions concentration

The proposed rate expressions are as follows:

$$
\begin{aligned}
& R_{(1)}=\frac{V_{m 1}[S 2][S 3]}{\left.k_{s}\left\{\frac{k h_{1}}{\left[H^{+}\right]}+1+\frac{\left[H^{+}\right]}{k h_{1}}\right)+k s_{2}\left[S_{2}\right]+k s_{3}\left[S_{3}\right]+[S 2][S 3]\right)} \\
& R_{(2)}=\frac{V m_{2}[S 1]}{\left.k s_{1}\left\{\frac{k h h_{2}}{\left[H^{+}\right.}+1.0+\frac{\left[H^{+}\right]}{k h h_{2}}\right\}+\left[S_{1}\right]+\left[S_{1}\right]\left[S_{1}\right] / k_{i}\right)}
\end{aligned}
$$

Putting the rate expressions R1,2 in a dimensionless forms, the resuls are equation $(3,4)$

$$
\begin{aligned}
& s_{1}=\frac{\left[S_{1}\right]}{k s_{1}} \quad s_{2}=\frac{\left[S_{2}\right]}{k s_{2}} \quad s_{3}=\frac{\left[S_{3}\right]}{k s_{3}} \quad \mathrm{~h}=\frac{\left[H^{+}\right]}{k h h_{2}} \quad \delta_{1}=\frac{K h h_{2}}{K h h_{2}^{\prime}} \\
& \delta_{2}=\frac{K h h_{2}}{K h_{1}^{\prime}} \quad \delta_{3}=\frac{K h_{1}}{K h h_{2}} \quad k d=\frac{K s_{s}}{K s_{2} K s_{3}}, \alpha=\frac{K s_{1}}{K m_{1}} \quad, \beta=\frac{K s_{2}}{K s_{3}} \\
& R_{(1)}=\frac{k d\left(\frac{\delta_{3}}{h_{1}}+1+\delta_{2} h\right)+\beta s_{2}+s_{3} / \beta+s_{2} s_{3}}{V m_{2} s_{1}} \quad(3) \\
& R_{(2)}=\frac{1 / h+1.0+\delta_{1} h+s_{1}+\alpha s_{1}{ }^{2}}{1 / h}
\end{aligned}
$$

where S12: acetylcholine S21: choline S31: acetate $\mathrm{H}$ : hydrogen ions the material balance equation for the two compartments can be summarized in dimensionless form as follows:

(1) For Hydrogen Ions $\left[\mathrm{H}^{+}\right]$:

(A) For compartment (1)

$\frac{d h_{(1)}}{d T}=\left(H_{f}-h_{(1)}\right)-\alpha_{h}\left(h_{(1)}-h_{(2)}\right)-\gamma\left(\frac{1}{H_{f}}-\frac{1}{h_{(1)}}\right)+\gamma \alpha_{o h}\left(\frac{1}{h_{(1)}}-\frac{1}{h_{(2)}}\right)$

(B)For compartment (2) 
$\frac{d h_{(2)}}{d T}=\alpha_{h} * V_{R} *\left(h_{(1)}-h_{(2)}\right)-\alpha_{o h} * \gamma^{*} V_{R}\left(\frac{1}{h_{(1)}}-\frac{1}{h_{(2)}}\right)+\beta_{1} * R_{(2)}$

Where $\mathrm{h}(\mathrm{j}), \mathrm{j}=1,2$ is the dimensionless hydrogen ions concentration, $T=q t / V_{(1)}$ is the dimensionless time, $V_{R}=\frac{V_{(1)}}{V_{(2)}}$ is the ratio of volume of the two compartments ( dimensionless), ${ }^{\alpha_{h}}$ is the dimensionless membrane permeability for hydrogen ions, ${ }^{\alpha h}$ is the dimensionless membrane permeability for hydroxyl ions .

\section{(2) For Acetylcholine Ach[S1]:}

(A)For compartment (1)

$\frac{d S_{1(1)}}{d T}=\left(s_{1 f}-s_{1(1)}\right)-\alpha_{s 1}\left(s_{1(1)}-s_{1(2)}\right)+\beta_{2} * R_{(1)}$

(B)For compartment (2)

$\frac{d s_{1(2)}}{d T}=\alpha_{S 1} * V_{R} *\left(s_{1(1)}-s_{1(2)}\right)-\beta_{3} * R_{(2)}$

where $\alpha_{s 1}$ is the dimensionless membrane permeability for acetylcholine

\section{(3) For Choline[S2]:}

$\frac{d s_{2(1)}}{d T}=\left(s_{2 f}-s_{2(1)}\right)-\alpha_{s 2}\left(s_{2(1)}-s_{2(2)}\right)-\beta_{4} * R_{(1)}$

(B)For compartment (2)

$\frac{d s_{2(2)}}{d T}=\alpha_{S 2} * V_{R} *\left(s_{2(1)}-s_{2(2)}\right)+\beta_{5} * R_{(2)}$

where $\alpha_{s 2}$ is the dimensionless membrane permeability for choline

(4) For Acetate[S3]:

(A)For compartment (1)

$\frac{d s_{3(1)}}{d T}=\left(s_{3 f}-s_{3(1)}\right)-\alpha_{s 3}\left(s_{3(1)}-s_{3(2)}\right)-\beta_{6} * R_{(1)}$

(B)For compartment (2)

$$
\frac{d s_{3(2)}}{d T}=\alpha_{S 3} * V_{R} *\left(s_{3(1)}-s_{3(2)}\right)+\beta_{7} * R_{(2)}
$$


where $\alpha_{s 3}$ is the dimensionless membrane permeability for acetate.

The relatively simple two-enzymes / two compartments model is thus represented by by the set of equations 1 through 8 which represents the nonlinear system of equations having eight state variables $\left[\mathrm{h}_{(\mathrm{j})}, \mathrm{S}_{1(\mathrm{j})}, \mathrm{S}_{2(\mathrm{j})}, \mathrm{S}_{3(\mathrm{j})}, \mathrm{j}=1,2\right.$ ]. The system parameters whose their values given in Table (1)

\section{3-Numerical tools , presentation techniques and computational resources:}

The static and dynamic bifurcation analysis were performed. The bifurcation parameter was taken as the feed concentrations of acetylcholine and hydrogen ions( S1f).The bifurcation diagrams are obtained using the software package AUTO 86 of Doedel and Kernevez [ 15 ] . This package is able to perform both steady state and dynamic bifurcation analysis , including the determination of entire periodic branches . In some cases where multiplicity of steady state exists in a very narrow range of the bifurcation parameter or where catastrophic changes in periodic branches occur, the AUTO 86 package fails to capture the complete periodic branches ; in these cases, simulation techniques are used to complete the whole picture of the bifurcation diagrams .

Poincaré presentation techniques are also used. The discrete points ( return points ) are obtained by the intersection between the trajectories and a hypersurface ( Poincaré surface ). These discrete points of intersection are taken such that the trajectories intersect the hypersurface transversally and cross it in the same direction .

A DGEAR subroutine for stiff differential equations, with automatic step size to insure accuracy, is used for numerical simulation of periodic and chaotic attractors . The differential equations of the present system are quite stiff and in many cases a bound on allowable error as small as $10^{-15}$ was necessary to obtain accurate results

\section{4- Results and Discussion}

The bifurcation analysis is concerned with the way that steady state solutions of the model equations vary with one of several system parameters.

The acetylcholine feed concentration ( S1f ) has been chosen as the main bifurcation parameter. In order to study the effects of different system parameters on the qualitative changes of bifurcation, the continuity diagrams for some of the model parameters (beta1, alfa, alfoh, Hf, Vr, del2, gamma, alfh, alfs1) are shown in Fig.(4-a) through Fig.(4-L).

In these diagrams the loci of the static limit points ( the dashed curves) and the loci of the Hopf bifurcation points ( the solid curves) has been shown as the system parameters vary with acetylcholine feed concentrtion ( S1f). These entire figures shows the presence of more than one HB point along a wide range of the system parameters. That means oscillation behavior ( periodic or non-periodic) occurrence.

Figure ( $4-\mathrm{a}$ ) shows the two parameter continuation diagram ( beta1 vs S1f). The figure shows sensitivity for ( beta1) changes across S1f changes, the loci of SLP shows a closed loop and it is in dashed lines, the loop shows regions of 2 or 3 SLPs, the loci of HB is in solid ones and show existence of two HB across the change in S1f from 0 to 35 .

Figure ( $4-\mathrm{b}$ ) represents the two parameter continuation diagram of ( alfa vs S1f), the figure shows sensitivity in the loci of HB points and SLPs across the change in S1f. There are regions of $2 \mathrm{HB}$ points but for SLPs there exist 2 SLPs or 4 SLPs.

Figure ( $4-\mathrm{c}$ ) represents the two parameter continuation of ( alfoh vs S1f), there exist a region of $2 \mathrm{HB}$ points and no sensitivity, and for SLPs it changes from 2 to 6 .

Figure $(4-\mathrm{d}$ ) represents the two parameter continuation diagram of ( Hf vs S1f. The loci of HB points consists of a loop and it vanishes at (0.015) while the dashed one (for SLPs) it consists of a loop in the start region and then it is fixed for 2 SLPs. 
Figure ( $4-\mathrm{e}$ ) represents the two parameter continuation diagram of ( $\mathrm{Vr}$ vs S1f). $\mathrm{Vr}$ represents $\mathrm{V} 1 / \mathrm{V} 2$, in the start , $2 \mathrm{HB}$ points exist then an isola starts to show beside a static solution which means a bistability case.

Figure ( $4-\mathrm{f}$ ) represents the two parameter continuation diagram of ( del2 vs S1f), the figure shows insensitivity to S1f changes, it consists of $2 \mathrm{HB}$ and it is constant all over the changes of S1f, for SLPs, 2 SLPs and constant all over the changes of S1f.

Figure ( $4-\mathrm{g}$ ) represents the two parameter continuation diagram of ( Gamma vs S1f ), in the start 2 HB , 2 SLPs exist and then a region of 4 SLPs and an isola at ( gamma $=0.033$ ), the system is rich in this figure with multiplicity phenomena occurrence.

Figure ( $4-\mathrm{h}$ ) represents the two parameter continuation diagram of ( Alfh vs S1f), the system is insensitive and no changes since $2 \mathrm{HB}, 2$ SLPs in the start of increase of S1f , then 2 $\mathrm{HB}, 4$ SLPs across the increase in S1f.

Figure ( $4-\mathrm{i}$ ) represents the two parameter continuation diagram of ( alfs1 vs S1f), $2 \mathrm{HB}, 4$ SLPs and constant from zero ( S1f ). The system is insensitive due to any change of S1f and it shows 2 HB , 4 SLPs across the increase of S1f.
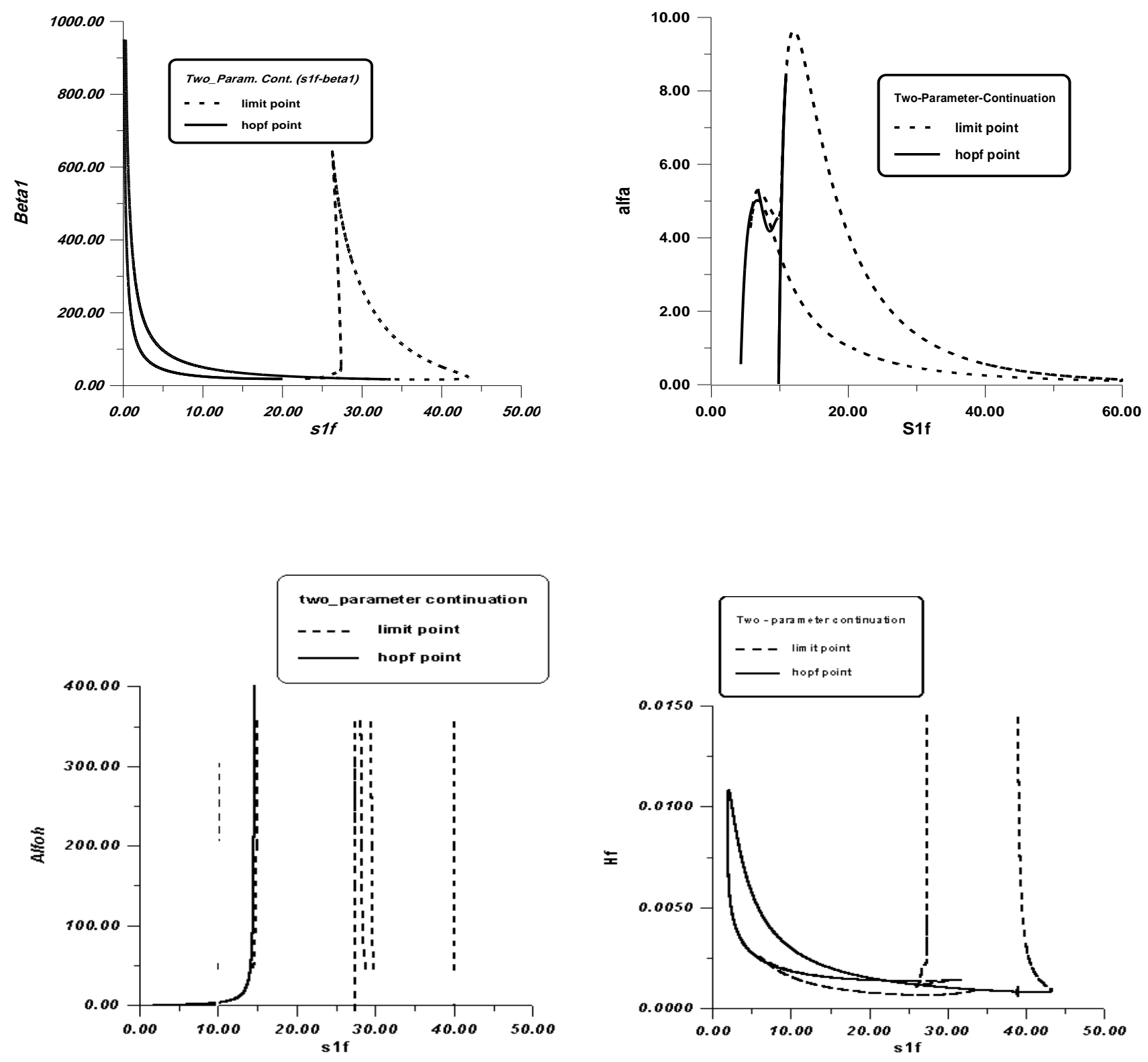

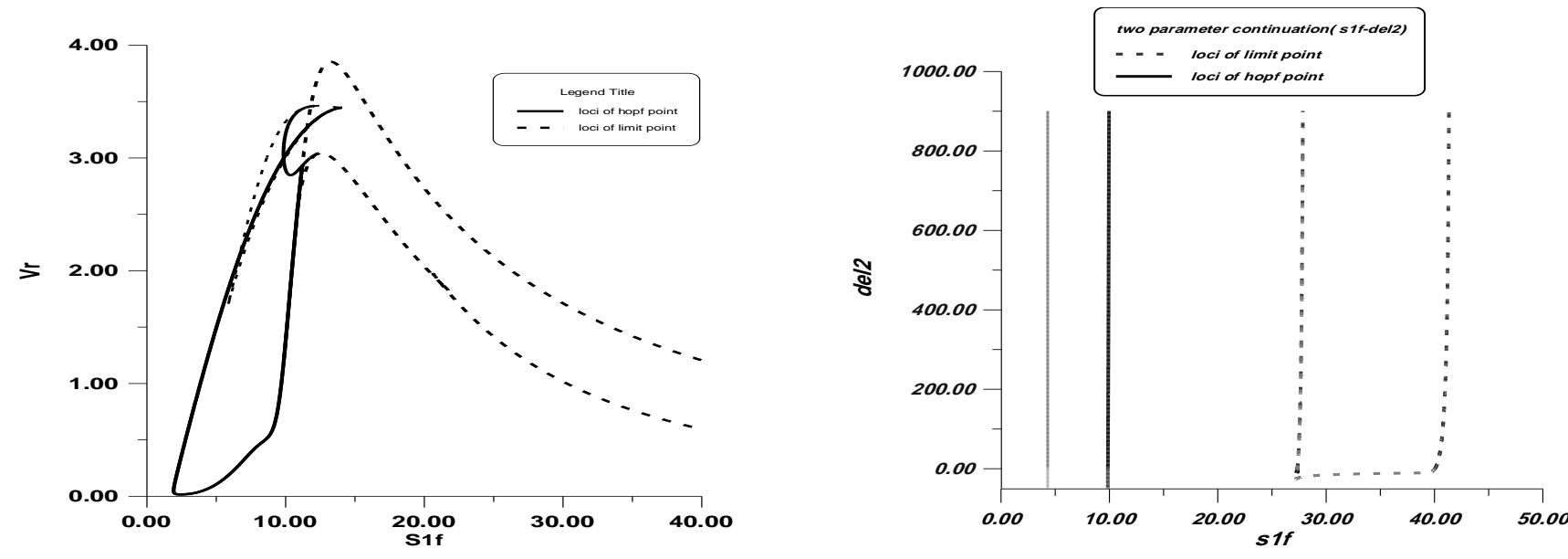

Figure (4) Two parameter continuation diagram for some of the model parameters

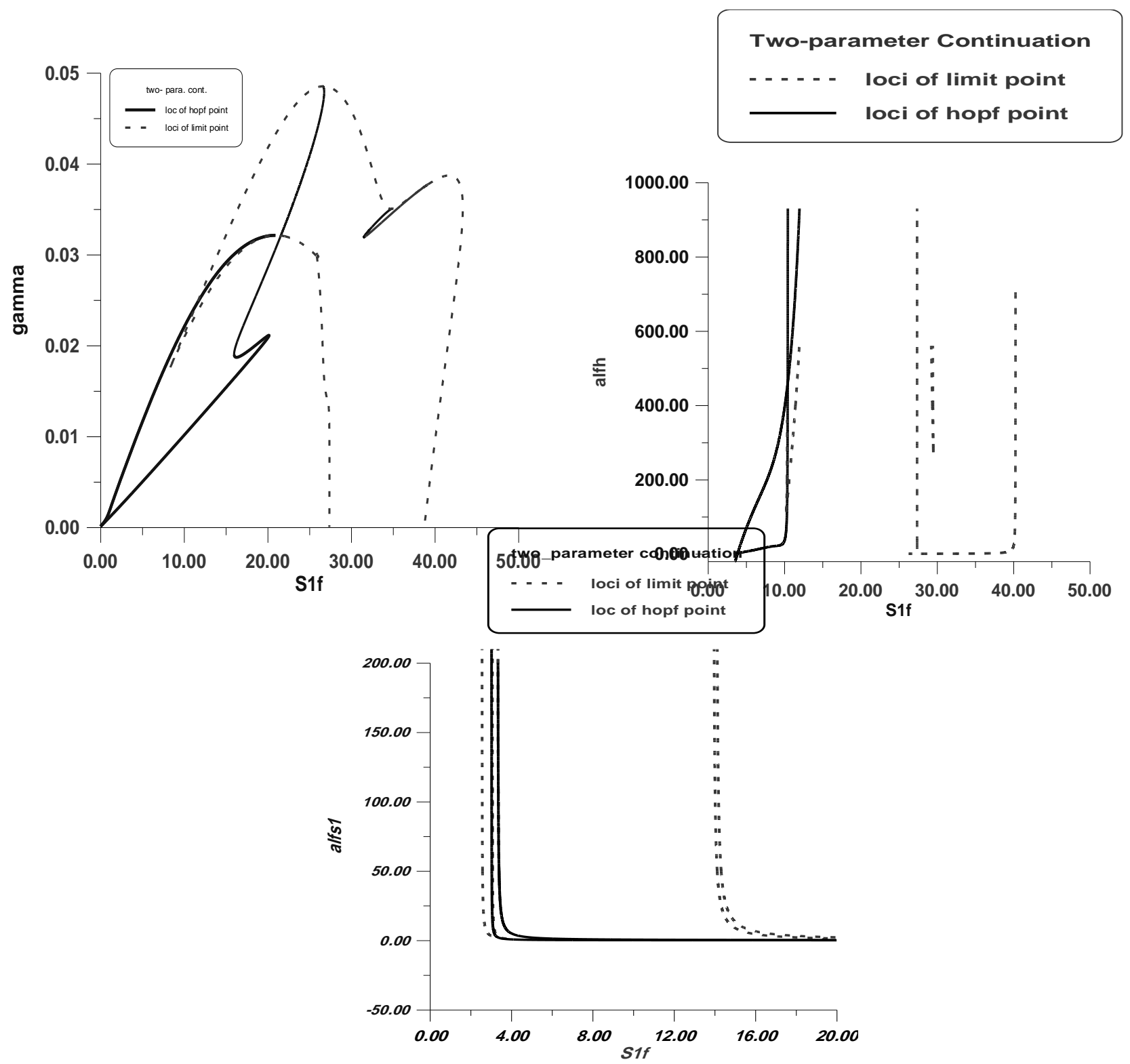


Figure (4) Two parameter continuation diagram for some of the model parameters(contd.)

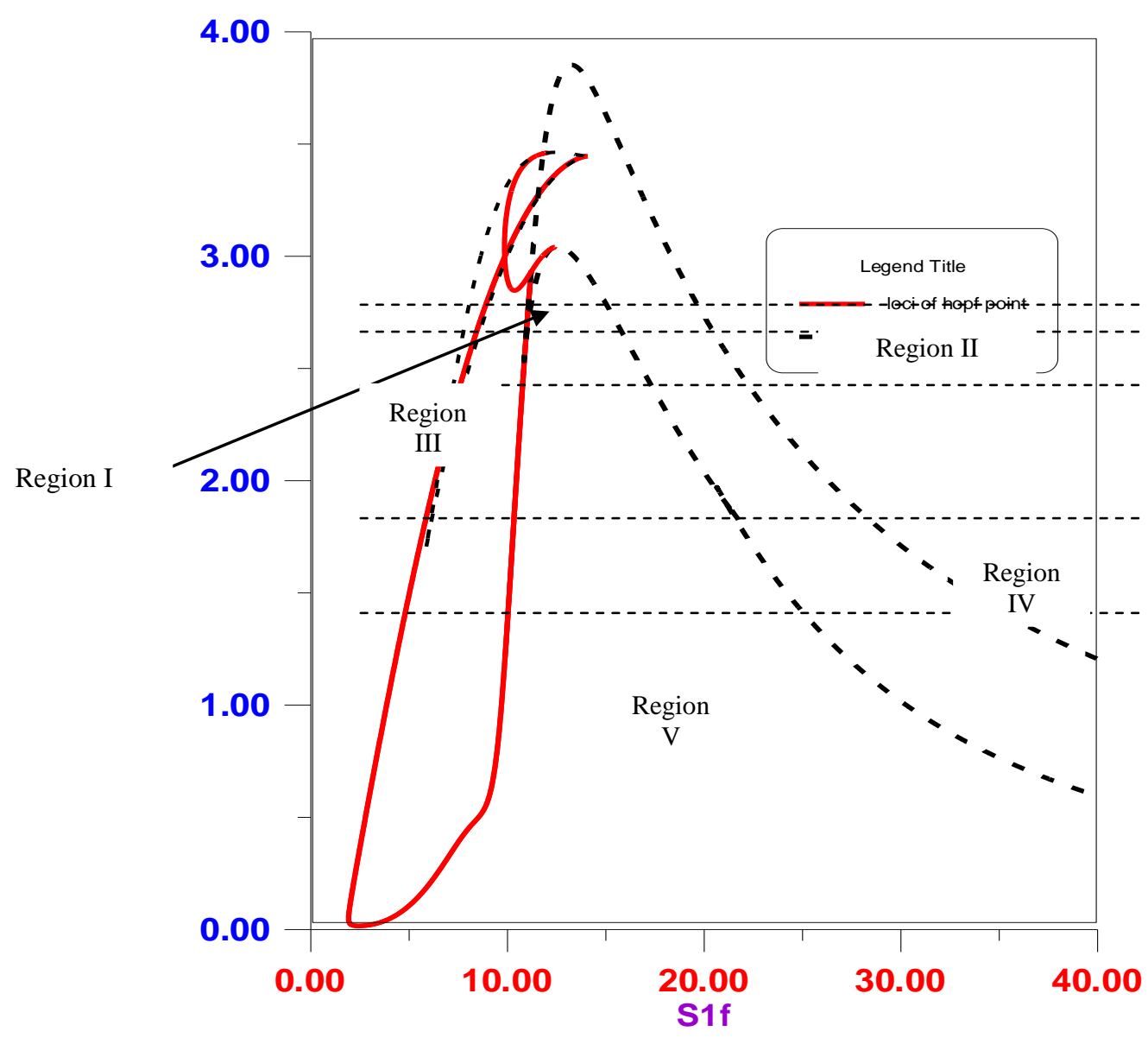

Figure ( 5 ) Regions of HB and LPs on ( Vr ) ( Two - parameter continuation )

To have better understanding of the different bifurcation in the system .Figure ( 5 ) id divided into different regions according to the presence of HB points and SLPs.

The static and dynamic bifurcation for each region are studied carefully, Different values of $\mathrm{Vr}$ are studied at different regions, each will have its bifurcation diagram . At $\mathrm{Vr}=4.0$ ( No multiplicity phenomena, and only static bifurcation exists, no HB or SLPs exists). At $\mathrm{Vr}=$ 3.1 , there exists a bistability ( $\mathrm{S}$-shape curve and an isola curve exist), at another values of $\mathrm{Vr}$ ( $\mathrm{Vr}=3.0$ or 2.8 or 1.9 or $\mathrm{Vr}=1.0$ ), there exists HB points and SLPs which means that periodic solution exists ( and in a nother words there exist an oscillation in the system). Noting that the system is more sensitive to a small variation in the value of $\mathrm{Vr}$ and depicts a different HB points and SLPs regions. 

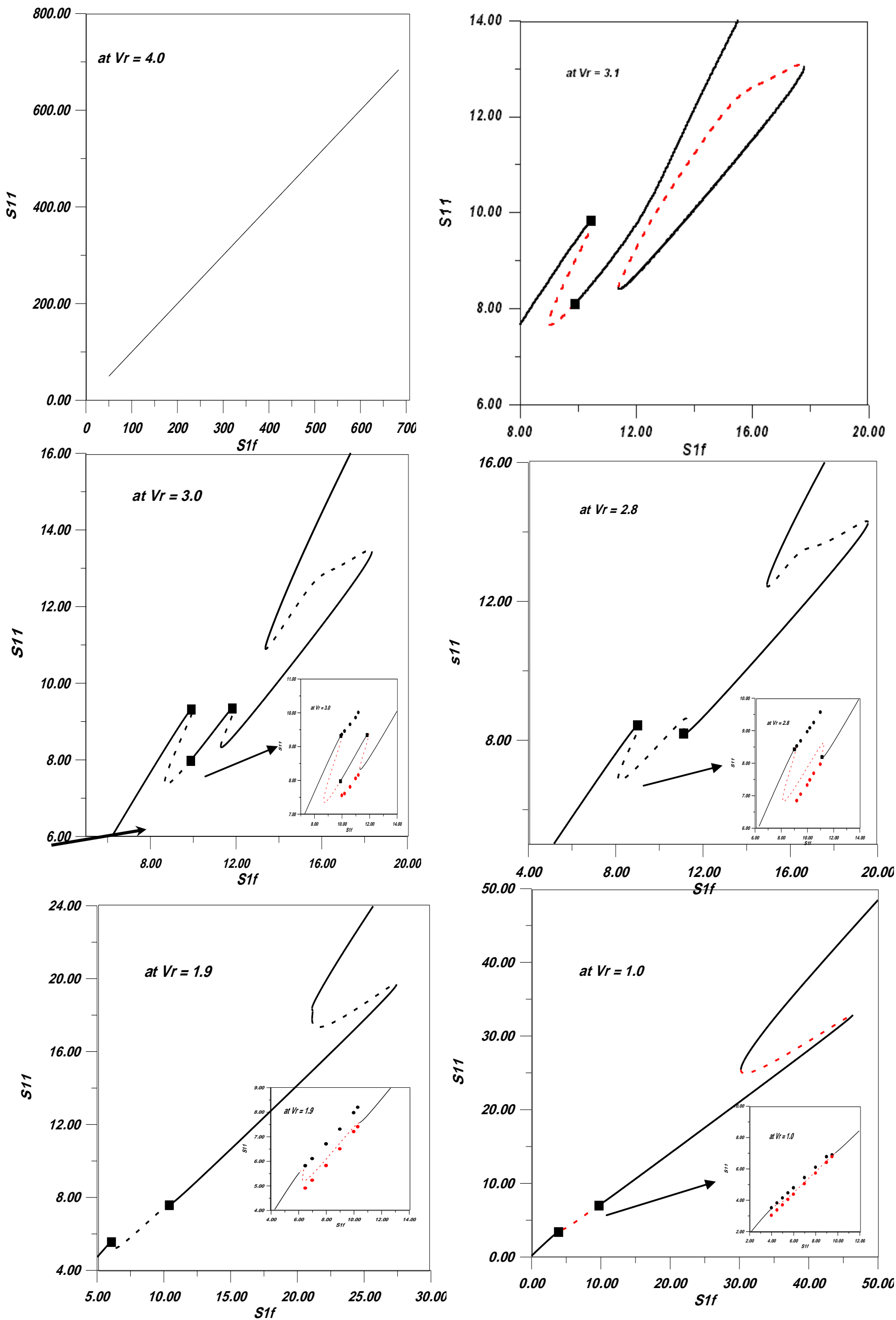
Figure(6) Continuity curves for different values of $\mathrm{Vr}$ in a different regions of twoparameter continuation curve

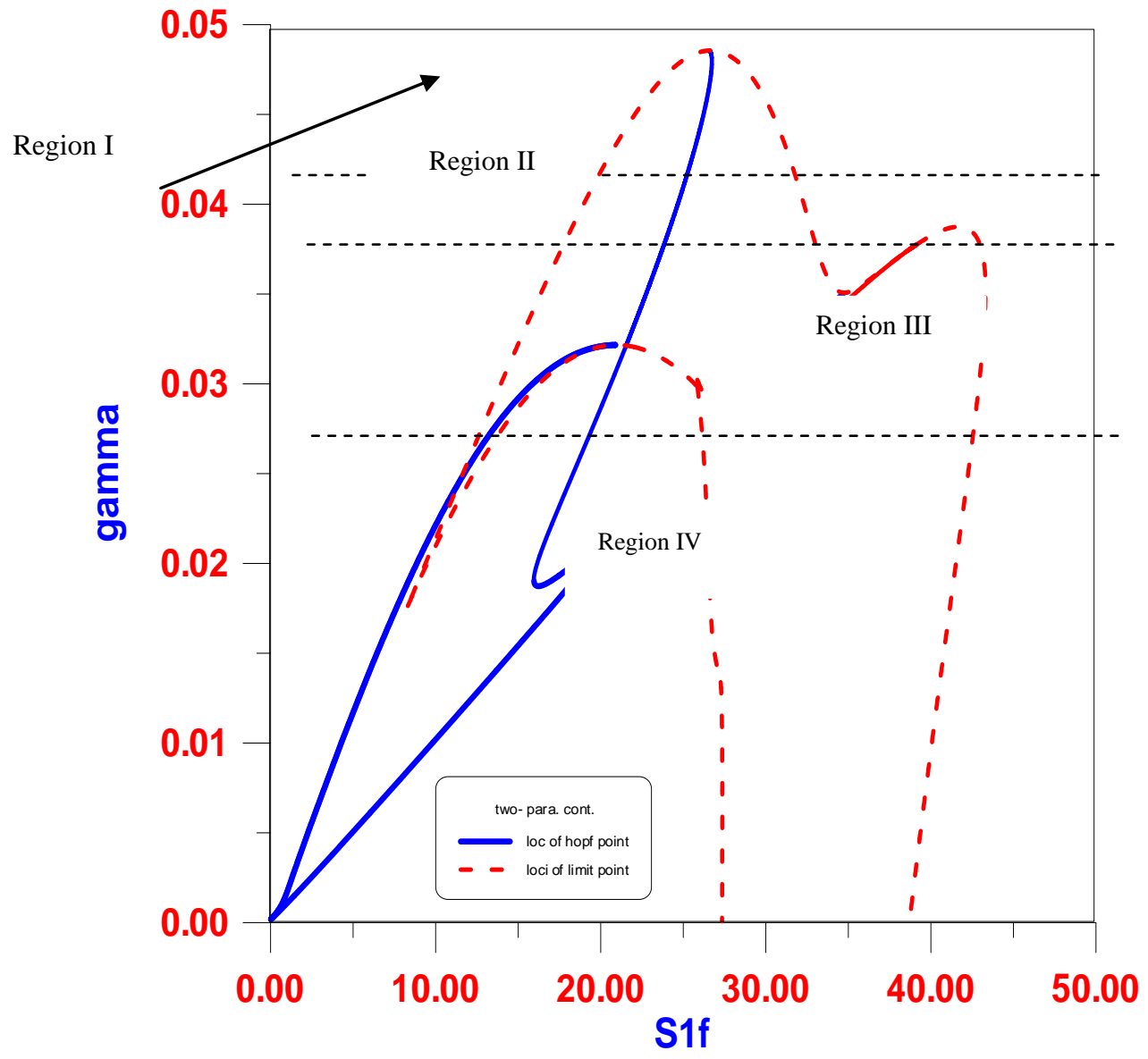

Figure ( 7 ) Regions of HB and LPs on (Gamma ) ( Two - parameter continuation )

Also Studying the behavior and the continuity equation for a different values of $\mathrm{Vr}$ in the different regions of the two-parameter continuation curve were indicated in Figure $(8)$. We note that at gama $=.060$ there is no multiplicity phenomena ( only static bifurcation curves exists ) and no LP or HB exists. At gama $=.033$ there exist a bistability ( static solution curve and isola curve exists). In the isola curve there exists $3 \mathrm{HBs}$ and there exists regions of stability and instability as shown in figure (8). At another different values of gama there exists HB points and SLPs which means that a periodic solution exists (and in a nother words there exist an oscillation in the system). Noting that the system is more sensitive to a small variation in the value of gama and the number of HB and LP points according to the value of gama.
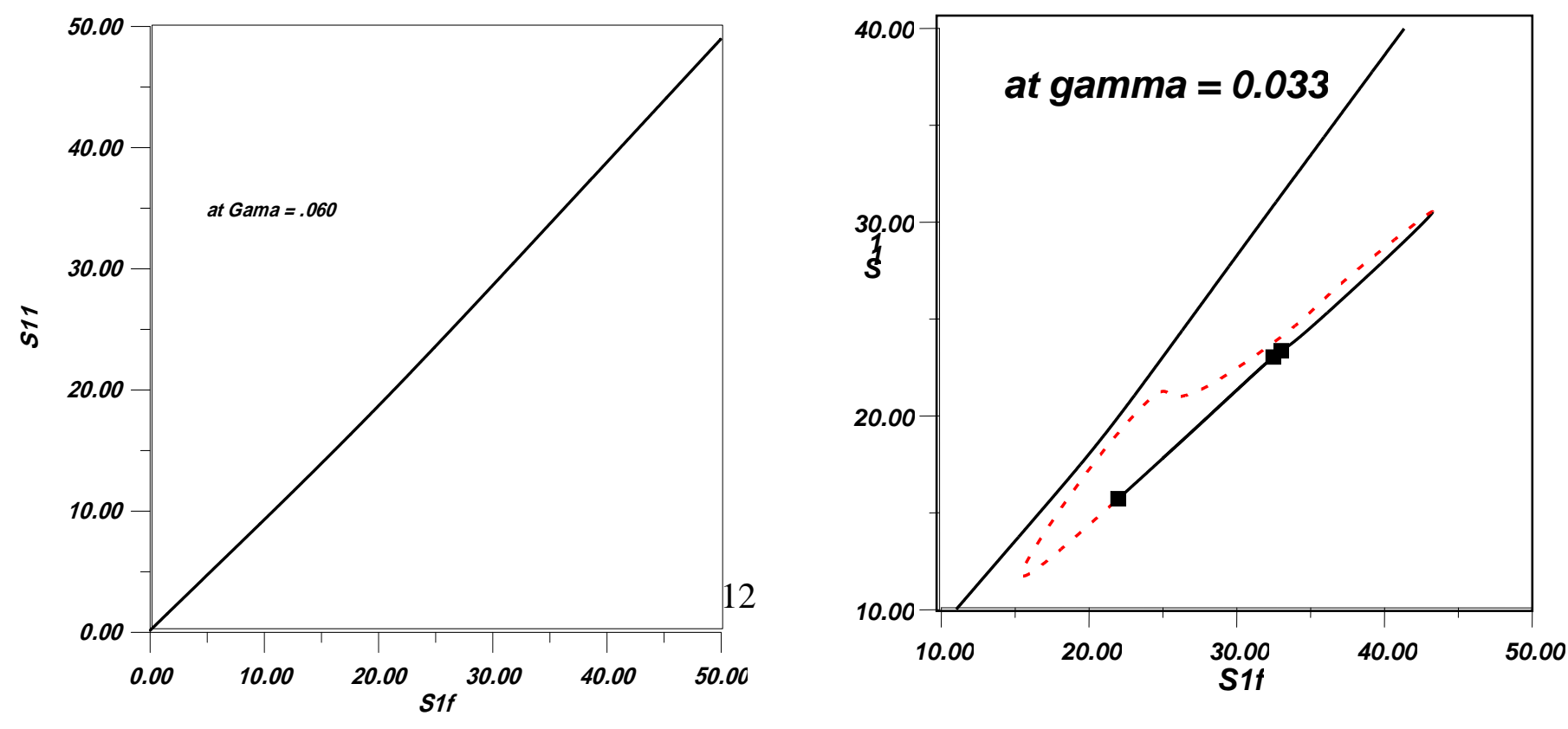

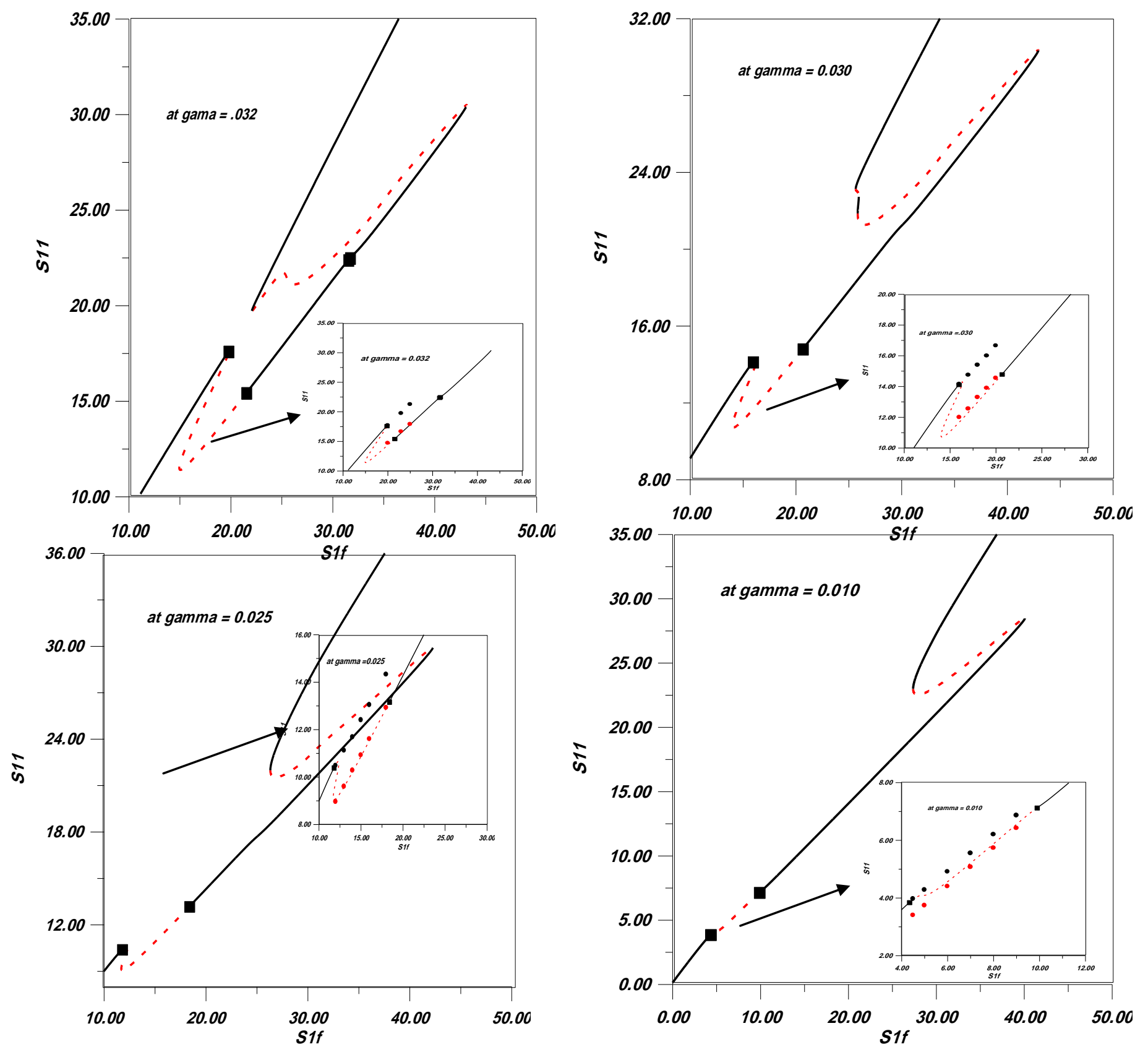

Figure(8) Continuity curves for different values of gama in a different regionsof twoparameter continuation curve

\section{5-Transition from bursting oscillation to smooth oscillations}

It is noted that there exists a gap between the curves of Poincare' map as shown in Figure (9-a ) but at $\mathrm{S} 1 \mathrm{f}=9.7773$ a bursting beside a smooth oscillation exists.

Increasing in S1f ( from 9.7773 to 9.7779 ) the bursting time decrease. Figure ( 10 ) shows that the transient time ( the time for transforming from burst to smooth ) decreases with increase of S1f 

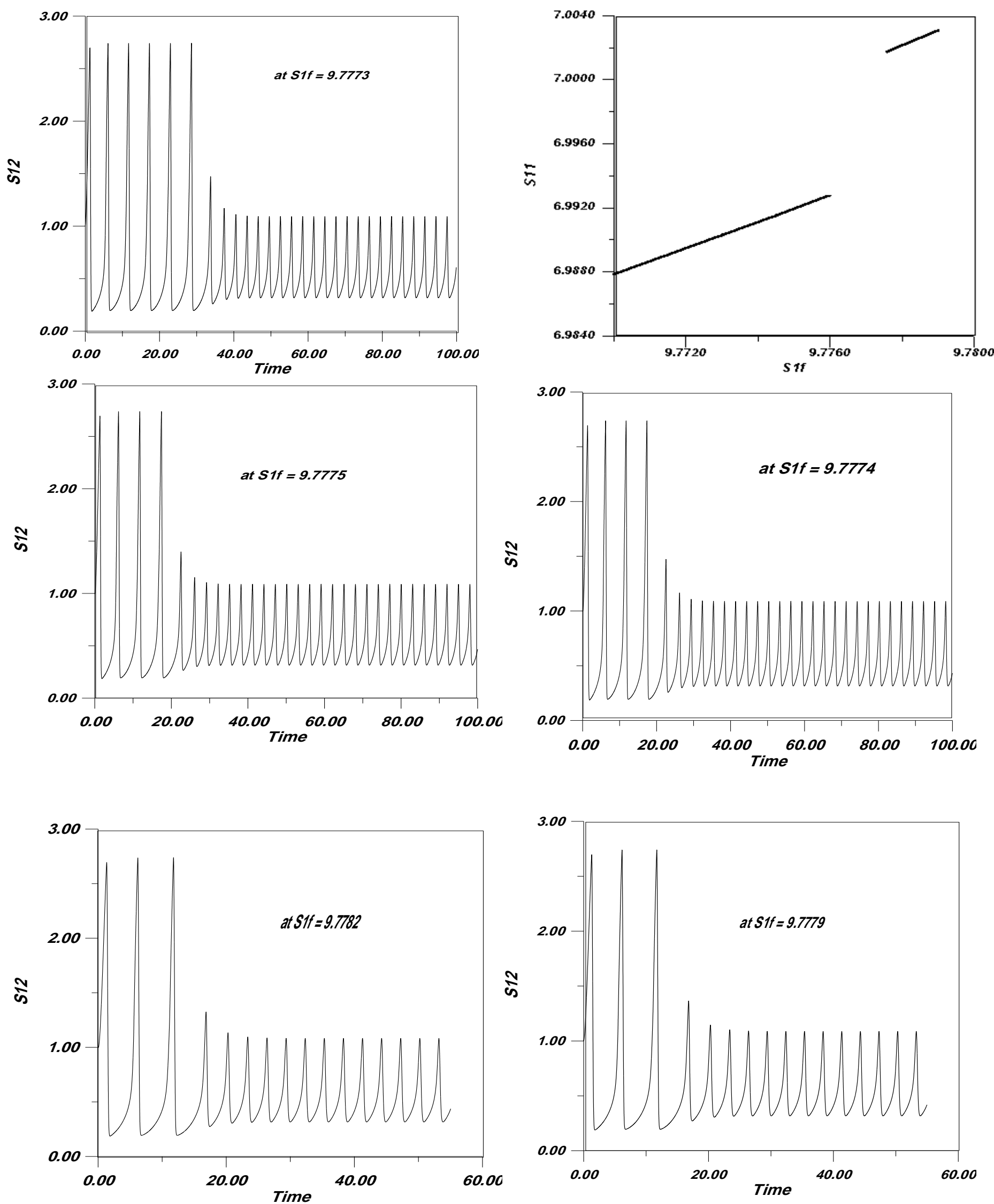

Figure 9 ) Transition from bursting oscillation to smooth oscillation 
Note: The more the bifurcation parameter ( S1f ) increase ,the less the transient time of the transient period

\begin{tabular}{||l|l||}
\hline S1f & Tt (transient time ) \\
\hline 9.7773 & 34 \\
\hline 9.7774 & 28 \\
\hline 9.7775 & 25 \\
\hline 9.7779 & 20 \\
\hline 9.7782 & 18 \\
\hline
\end{tabular}

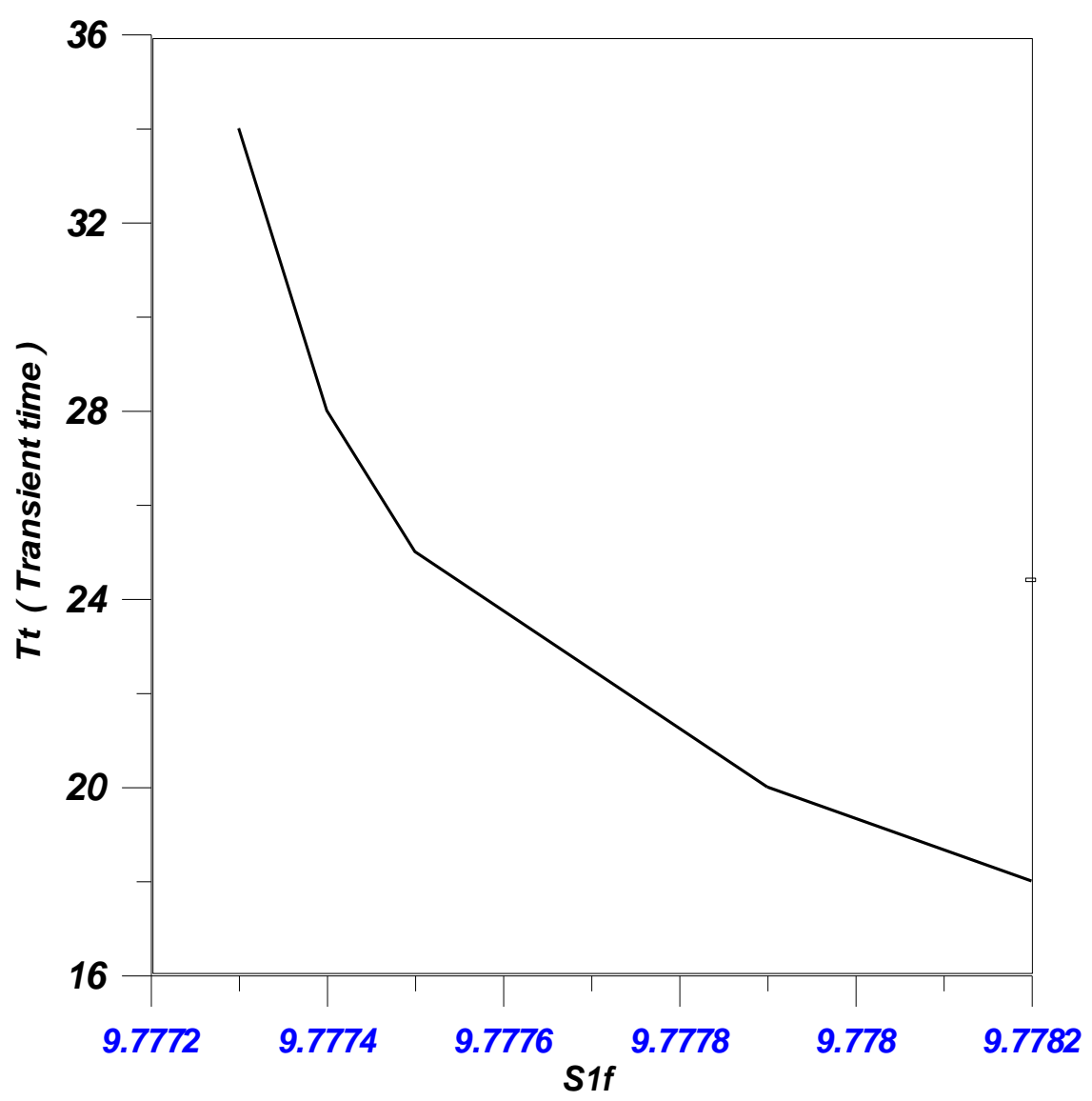

Figure ( 10 ) relation between bifurcation parameter and transient time $\mathbf{T t}$

Poincaré map is also investigated in the start of the periodic solution period and the result was shown in Figure ( 11 ), The period one attractor undergoes a period doubling sequence to give chaos ( chaos is obtained through a period doubling sequence). 


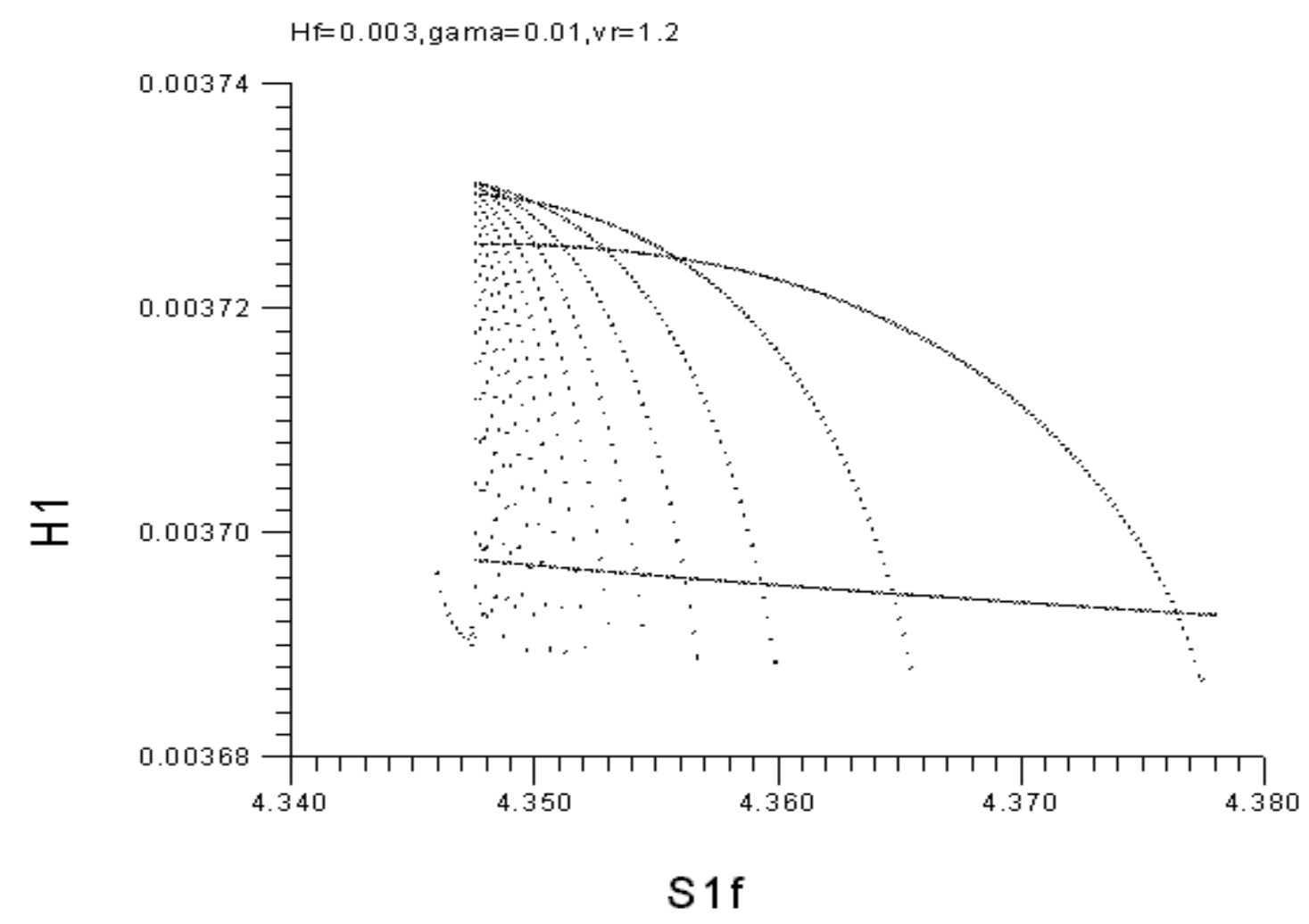

Figure ( 11 ) Poincaré map

\section{6-Conclusion :}

All the state variables are very sensitive to the variation of the acetylcholine inlet concentration (S1f) as a bifurcation parameter. Their behavior is strongly dominated by hysteresis and multiplicity phenomena for a large range of the bifurcation parameter. Different kinds of solutions also exist. Point ( Steady state ), Periodic and bistability are found. The system parameters were summarized in Table (1). The values were gathered from an extensive search in the literature. All concentrations are given in units of $\left(\mathrm{Kmol} / \mathrm{m}^{3}\right)$.

It has been found that some state variables and kinetic enzymatic equations are corresponding to the expected physiological values in some regions This can direct future experimental research in order to use this novel eight dimensional model for simulating real physiological behavior. Availability of good experimental data for human brain in future can help to greatly improve this model for deeper understanding of the physiological behavior and can help in planning better brain experiments and linking the complex behavior investigated in this paper to the cholinergic disorders and diseases. 
Table ( 1 )

\begin{tabular}{|l|l|}
\hline Parameter & Value \\
\hline$H_{f}$ & 0.003 \\
$S 1 f$ & 2.0 \\
$S 2 f$ & 2.0 \\
$\delta 1$ & .1 \\
$\delta 2$ & .1 \\
$\delta 3$ & .5 \\
$K d$ & 1 \\
$\alpha$ & .55 \\
$\beta$ & .5 \\
$\beta 1$ & 50 \\
$\beta 2$ & 10 \\
$\beta 3$ & 50 \\
$\beta 4$ & 100 \\
$\beta 5$ & 50 \\
$\beta 6$ & 50 \\
$\beta 7$ & 50 \\
$\alpha_{h}$ & 30 \\
$\alpha_{o h}$ & .5 \\
$\alpha_{s 1}$ & .5 \\
$\alpha_{s 2}$ & .5 \\
$\alpha_{s 3}$ & .5 \\
$\gamma$ & 0.033 \\
$V_{R}$ & 1.2 \\
\hline
\end{tabular}

\section{5- References :}

1-A.Maheca-Botero , P.Garhyan and S.S.E.H.Elnashaie, Modeling, Bifurcation and chaotic behavior of a coupled Acetylcholinesterase/choline Acetyltransferase Enzymes Neurocycle, mathematical and computer modeling 0,1-0 (2005)

2-Louis B. Hersh ,Martha Peet, Re-evaluation of the kinetic mechanism of the choline Acetyltransferase reaction, The journal of biological chemistry, vol (252) no 14, issue of july 25, P.P (4796-4802), ( 1977)

3-C.A.Guyton , Medical physiology , $7^{\text {th }}$ edition W.B.Saunders company, philadelphia , (1986).

4- S.Tucek ,. Acetylcholine Synthesis in Neurons ,Chapman and Hall , London (1978)

5- T.E.Barman, Enzyme Handbook, Vol.1 Springer-Verlage, New York , (1969).

6- http://www.biology.ucsd.edu/classes/bibc102.WI99/neuro/Neurotransmitter.html

7- H.Soreq and H.Zakut, Human Cholinsterases and Anticholinesterases, Academic Press , San Diego, (1993).

8- P.Kasa, Z. Rakonczay and K.Gulya ,The cholinergic system in Alzheimer's disease ,progress in Neurobiology 52,511-535,(1997).

9- H.Israel, Y.Mitsu and F.Abraham. , The cholinergic system in Alzheimer's disease, progress in Neurobiology 52,511-535,(1997). 
10-Alzheimer, A. Uber einen eigenartigen schweren Erkrankungsprozeb der Hirnrinde. Neurologisches Centralblatt (Lecture presented at the $37^{\text {th }}$ meeting of the southwest German psychiatrists in Tubingen), 23, 1129, ( 1906)

11-Bailey, J.E.; Ollis, D.F. Biochemical Engineering Fundamentals; McGraw Hill: New York (1977).

12-Bradley, P.B.; Fink, M. Anticholinergic Drugs and Brain Functions in Animals and Man; Elsevier Publishing Company: Amsterdam (1968).

13-Chay, R.R.; Rinzel, J. Bursting, beating and chaos in an excitable membrane model. Biophys. J., 47, 357 (1985).

14-Dixon, M.; Webb, E.C. Enzymes; Academic press: New York (1979).

15-Doedel, E.J.; Champneys, A.R.; Fairgrieve, T.F.; Kuznetsov, Y.A.; Sandstede, B.; Wang, X.J. AUTO97: Continuation and bifurcation software for ordinary differential equations. Department of Computer Science, Concordia University, Montreal, Canada, (1997).

16-Elnashaie, S.S.E.H.; El-Rifai, M.A.; Ibrahim, G. The effect of hydrogen ion production on the steady-state multiplicity of substrate inhibited enzymatic reactions. I. Steady-state considerations. Appl.Biochem. Biotechnol. , 8, 275. (1983).

17-Elnashaie, S.S.E.H.; El-Rifai, M.A.; Ibrahim, G. The effect of hydrogen ion production on the steady-state multiplicity of substrate inhibited enzymatic reactions. II. Transient behavior. Appl.Biochem. Biotechnol. , 8, 467 ( 1983).

18-Elnashaie, S.S.E.H.; El-Rifai, M.A.; Ibrahim, G. The effect of hydrogen ion production on the steady-state multiplicity of substrate inhibited enzymatic reactions. III. Asymmetrical steady-states in enzyme membranes. Appl.Biochem. Biotechnol. , 9, 455.( 1984).

19-Elnashaie, S.S.E.H.; Elshishini, S.S. Dynamic Modelling, Bifurcation and Chaotic Behavior of Gas-Solid Catalytic Reactor. Gordon and Breach Publishers, London, UK, (1996).

20-Elnashaie, S.S.E.H.; Harraz, H.M.; Abashar, M.E. Homoclinical chaos and the periodadding route to complex non-chaotic attractors in fluidized bed catalytic reactors, Chaos Solit. Fract., 12(10), 1761(2001)..

21-Elnashaie, S.S.E.H.; Ibrahim, G.; Teymour, F. A. Chaotic behavior of an acetylcholinesterase enzyme system. Chaos, Solitons \& Fractals. , 5, 933.( 1995).

22-El-Rifai, M.A.; Elnashaie, S.S.E.H.; Aboulfath, H. Effect of feedback inhibition on the behavior of multienzyme monolinear reaction chains. J. Solid-Phase Biochem, 5, 235.(1980).

23-Ermentrout, B. Simulating, Analyzing, and Animating Dynamical Systems: A Guide to Xppaut for Researchers and Students; SIAM: New York (2002).

24-Fan, Y.S. and Holden, A.V., Bifurcation, bursting, chaos and crisis in the Rose-Hindmarsh model for neuronal activity, Chaos, Solitons \& Fractals, 3(4), 439 (1993).

25-Feigenbaum, M.L. Universal behavior in nonlinear systems. Los Alamos Sci. , 1, 4.( 1980).

26-Fitzhugh, R. Impulses and physiological states in theoretical models of nerve membranes.

Biophys. J. , 1, 445.( 1985).

27-Friboulet, R.; David, A.; Thomas, D. Excitability memory and oscillation in artificial acetylcholinesterase membranes. J. Membr. Sci. , 8, 33,(1981).

28-Guyton, C.A.; Hall, J.E. Textbook of Medical Physiology, $10^{\text {th }}$ Ed.; W. B. Saunders Company: Amsterdam (2000).

29-Hindmarsh, J. L. and Rose, R. M., A model of neuronal bursting using three coupled first order differential equations, Proc. Roy. Soc., B221(1222), 87 (1984).

30-Hindmarsh, J. L. and Rose, R. M., A model of the nerve impulse using two first-order differential equations, Nature, 296(5853), 162 (1982).

31-Holden, A.V. and Fan, Y.S., Crisis-induced chaos in the Rose-Hindmarsh model for neuronal activity, Chaos, Solitons \& Fractals, 2(6), 583 (1992c). 
32-Holden, A.V. and Fan, Y.S., From simple to complex oscillatory behaviour via intermittent chaos in the Rose-Hindmarsh model for neuronal activity, Chaos, Solitons \& Fractals, 2(4), 349 (1992b).

33-Holden, A.V. and Fan, Y.S., From simple to simple bursting oscillatory behaviour via chaos in the Rose-Hindmarsh model for neuronal activity, Chaos, Solitons \& Fractals, 2(3), 221 (1992a).

34-Ibrahim, G; Elnashaie, S.S.E.H. Hyperchaos in acetylcholinesterase enzyme systems. Chaos, Solitons \& Fractals. , 8, (1977).

35-Ibrahim, G; Teymour, F.A.; Elnashaie, S.S.E.H. Periodic and chaotic behavior of substrate-inhibited enzymatic reactions with hydrogen ions production. Appl. Biochem. Biotechnol. , 55, 175,( 1995).

36-Koch, A.L., The $\mathrm{pH}$ in the neighborhood of membranes generating a protomotive force, $J$. Theor. Biol., 120, (1986).

37-Kubicek, M.; Marek, M. Computational methods in bifurcation theory and dissipative structures. Springer Verlag, New York, (1983).

38-Kysela, S.; Torok, J. Histamine H1-receptor antagonists do not prevent the appearance of endothelium-dependant relaxation to acetylcholine in rat pulmonary artery. Physiol. Res. , 45(4), 345(1996).

39-Llinás, R.R., The Squid Giant Synapse: A Model for Chemical Transmission; Oxford University Press: London (1999).

40-Naparrstek, A.; Romette, J.L.; Kernevez, J.P.; Thomas, D. Memory in enzyme membranes. Nature. , 249, 460,( 1974).

41-Páez, M.C.; and Fayad, R. Diffusion of the neurotransmitter cannot govern the rise time of miniature end-plate. Revista Colombiana de Física. , 31, 163.( 1999).

42-Parkinson, J. Essay on Shaking Palsy; London: 1817.

43-Quinn, D.M.; Balasubremanian, A.S.; Doctor, B.P.; Taylor, P. Enzymes of the Cholinestrase Family; Plenum Press: London (1995).

44-Rae, C.; Scott, R.; Thompson, C.H.; Dumughn, I.; Kemp, G; Styles, P.; Tracey, I.M.; Radda, G.K. Is brain pH a biochemical marker of IQ? Proc. R. Soc. London, Ser. B. , 262, 1061,(1996).

45-Silver, A. The Biology of Cholinestrases; North-Holland Publishing Company: Amsterdam (1974).

46-Soreq, H; Xakut, H. Human Cholinestrases and Anticholinestrases; Academic Press: New York (1993).

47-Wessler, I.; Roth, E.; Schwarze, S.; Weikel, W.; Bittinger, F.; Kirkpatrick, C.J.; 48Kilbindger, H. Release of non-neural acetylcholine from the human placenta: difference to neural acetylcholine. Naunyn-Schmiedeberg's Arch. Pharmacol, 364, 205,( 2001)

49-Zauner, A.; Muizelaar, J.P.; Brain metabolism and cerebral blood flow. Head Injury: Pathophysiology and Management of Severe Closed Injury, Eds. Reilly, P; Bullock, R; Chapman and Hall: London (1997). 